\title{
Comparison of the effectiveness of manual massage, long-wave diathermy, and sham long-wave diathermy for the management of delayed-onset muscle soreness: a randomized controlled trial
}

\author{
Lorenzo Visconti ${ }^{i^{*}}$ (D), Corrado Forni ${ }^{2}$, Rudi Coser ${ }^{3}$, Marco Trucco ${ }^{4}$, Elisa Magnano ${ }^{5}$ and Gianpiero Capra ${ }^{6}$
}

\begin{abstract}
Background: Delayed-onset muscle soreness (DOMS) is a specific symptom that typically arises after unaccustomed eccentric muscular effort. It increases typically $24-72 \mathrm{~h}$ post-exercise and can affect physical performance. The pathophysiology of DOMS remains unclear, although it seems to be related to the remodeling phase of myofibrils. Different types of treatments have been proposed to minimize DOMS after exercise; however, no clear gold standard treatment exists. Among the most popular and easy-to-apply treatments, manual massage is often performed by clinicians and has been documented to be effective in reducing symptoms. For several years, longwave diathermy (LWD) has been performed to manage musculoskeletal complaints, such as DOMS; however, no studies have reported its efficacy thus far.

This study aimed to compare the clinical effectiveness of LWD, sham LWD, and manual massage in participants with lower limb DOMS.

Methods: Participants with lower limb DOMS were included in the study. They were randomly assigned to undergo real LWD, sham LWD, or manual massage. The Numeric Pain Rating Scale (NPRS) score was the primary outcome, and the Patient Global Impression of Change (PGIC) Scale score was the secondary outcome. Outcomes were collected before and immediately after the treatment. Analysis of variance was performed to compare the post-treatment NPRS value variability among the groups and to compare the pre- and post-treatment NPRS differences among the groups.
\end{abstract}

Results: No clinically relevant differences were observed regarding the NPRS value variability among real LWD, sham LWD and manual massage groups. Differences were observed in the PGIC Scale scores.

Conclusions: Future studies are needed to have a better understanding about the treatment of DOMS in clinical practice.

Trial registration: The trial was registered on 29th February 2016 in ClinicalTrials.gov (NCT02693678).

Keywords: DOMS, Lower extremity, Long-wave diathermy, Manual massage

\footnotetext{
* Correspondence: loppiski@gmail.com

${ }^{1}$ Studi fisioterapici di Montagna, Rue Palleusieux 111010 Pré-Saint-Didier,

Aosta, Italy

Full list of author information is available at the end of the article
}

(c) The Author(s). 2020 Open Access This article is distributed under the terms of the Creative Commons Attribution 4.0 International License (http://creativecommons.org/licenses/by/4.0/), which permits unrestricted use, distribution, and reproduction in any medium, provided you give appropriate credit to the original author(s) and the source, provide a link to the Creative Commons license, and indicate if changes were made. The Creative Commons Public Domain Dedication waiver (http://creativecommons.org/publicdomain/zero/1.0/) applies to the data made available in this article, unless otherwise stated. 


\section{Background}

Delayed-onset muscle soreness (DOMS) is one of the most common complaints of clinicians working in the sports field [1]. Soreness, which typically occurs 24-72 h post-exercise, is observed in the muscle especially after heavy eccentric exercise [2]. Although DOMS was believed to be caused by sarcolemma injury, the pathophysiology of DOMS remains unclear, and a recent study has highlighted the relationship between DOMS and myofibril remodeling [3]. DOMS has an impact on physical performance, as it affects coordination, muscle strength, and abilities to absorb shock [4, 5]. Different treatments have been proposed to manage DOMS [6]. As the pathophysiology of DOMS is unclear and no clear gold standard treatment has been established for managing DOMS, treatments range from applying heat, cold, compression, and massage [6-8]. As DOMS affects physical performance, it is of utmost importance, especially in the field of professional sports, that athletes can be immediately relieved from DOMS so that they can be trained or can compete with the absence of such conditions. Moreover, it is important for DOMS to be treated using easy-to-perform strategies, as sport teams are often engaged in traveling during competitions.

Manual massage is considered one of the most common and easy-to-perform treatments to relieve DOMS in clinical practice, and many authors have described its applications [9-12]. Moreover, long-wave diathermy (LWD; also known as capacitive and resistive electric transfer therapy) has recently received great clinical interest in the field of sports. LWD produces heat and is supposed to improve microcirculation flow and metabolic processes; however, currently, evidence of its presumed induced effect is insufficient. Clinical use of LWD in treating DOMS has been common since 2000. Heat has been suggested to relieve DOMS [8]. Despite the wide use of LWD in clinical practice, since more than a decade, and a recent study on the effect of such treatment on recovery in recreational runners [13], a study that confirms the efficacy of such treatment in DOMS does not exist.

This study aimed to investigate the effects of manual massage, real LWD (rLWD), and sham LWD (sLWD) on pain and its post-treatment effects in a group of athletes presenting with lower limb DOMS.

\section{Methods}

In this study, male athletes with lower limb DOMS were recruited. The participants were ski mountaineering racers who participated in a 3-day race, the 18th Millet Tour du Rutor Extreme (Arvier, Italy). The ski mountaineering alternate uphill phase with downhill free-ride ski exposing the athletes to highly sustained eccentric effort over the 3-days race (Fig. 1). The participants were treated during their rest time between stages while they were experiencing the peak phase of DOMS. The participants were excluded in this experiment if, during assessment, they complained of musculoskeletal or general health problems other than DOMS. Two senior-level physiotherapists, unaware of the group of treatments that participants would be assigned to, assessed the eligibility criteria in the study. The participants were randomly assigned, using an online software program (random.org), to the three treatments, with the assignment of treatment conducted by an undergraduate physiotherapy students at the end of their bachelor's degree. They treated the athletes with lower limb DOMS during its peak phase, from 24 to $72 \mathrm{~h}$ post-exercise according to data from the literature [2-10].

Sample size calculation was based on a mean change of 2 points in the Numerical Pain Rating Scale (NPRS) score, which is clinically relevant for musculoskeletal pain [14]. To detect a difference of 2 NPRS points, considering a standard deviation of 1.5 , a power $1-\beta$ of 0.8 , and a probability of type-I $\alpha$ error of $0.05,51$ participants (17 per group) were required in this experiment.

Consent to perform the study was obtained from the local ethics committee Azienda Ospedaliera Della Valle d'Aosta prot. nr 6719 22/1/2015, and all the procedures conformed to the Declaration of Helsinki. All the participants provided informed consent for inclusion in the study. The trial was preventively registered in ClinicalTrials.gov (NCT02693678).

\section{Treatments}

The participants were randomly divided into three groups. The participants allocated to the manual massage group were treated with manual massage as described in another study ${ }^{7}$. A 10 -min pain-free effleurage was performed in both limbs, with particular emphasis on the areas reported to be symptomatic with DOMS according to the athletes, was performed. The participants lay in the prone position for the treatment of the muscles of the posterior compartment of the lower limb (hamstrings and triceps surae) and in the supine position for the treatment of the muscles of the anterior compartment (quadriceps and foot dorsiflexors).

Participants allocated to the rLWD group were treated with switched-on LWD (Red Coral, Tecnosix, Sixtus, Italy). A 10-min treatment on the symptomatic areas in capacitive mode $(750 \mathrm{kHz})$ was performed. The device producers directly gave the instructions in the performance of the technique.

Participants allocated to the sLWD group were treated with switched-off LWD. The treatment was a 10-min switched off LWD (Red Coral Tecnosix, Sixtus, Italy) on the symptomatic areas. To perform sLWD, the device was switched-on for $10 \mathrm{~s}$ to provide warmth and then 


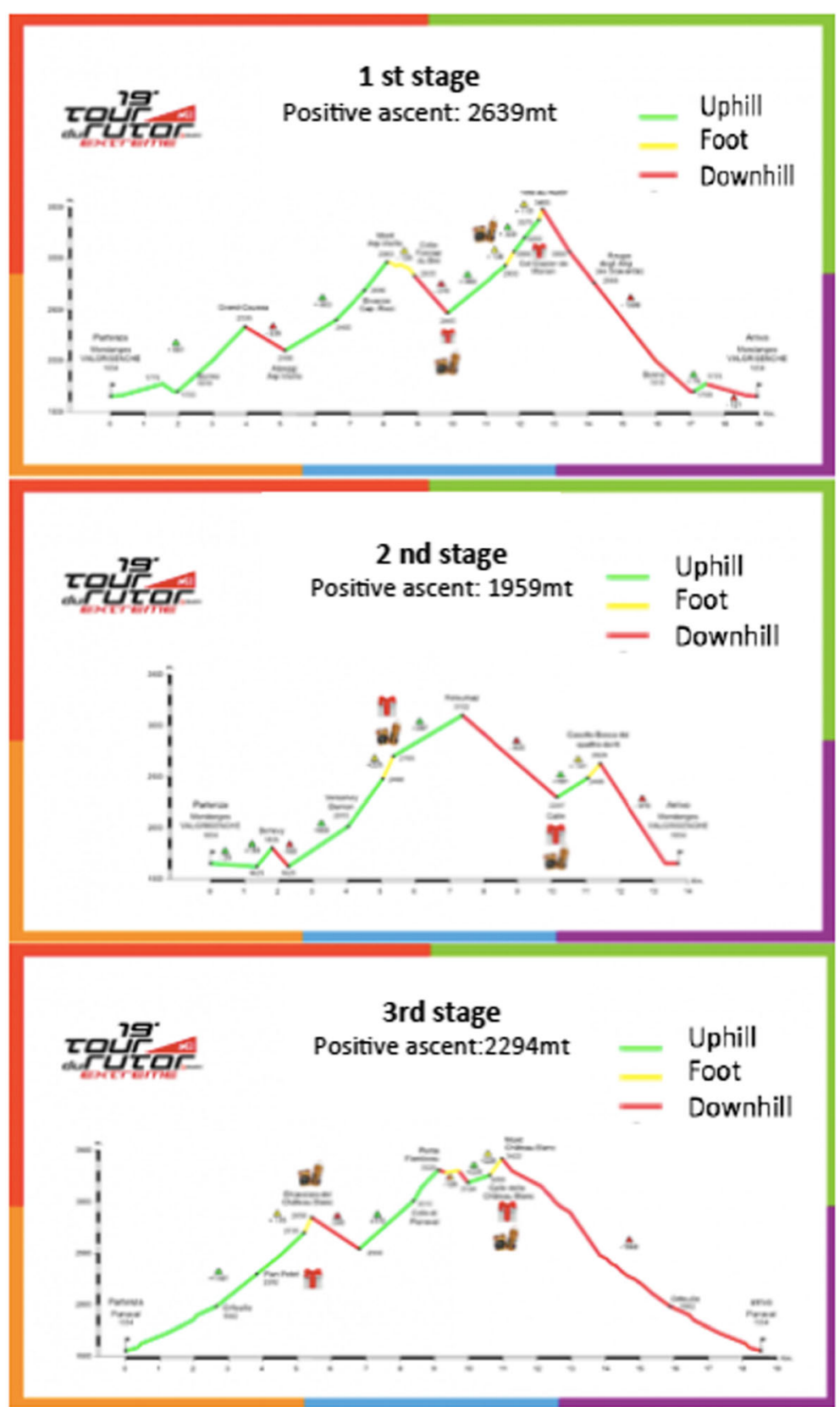

Fig. 1 18th Millet Tour du Rutor Extreme stages

switched-off for the rest of the treatment session. Participants were unaware that the device was switched-off, and two different operators performed the switching on and off of the LWD device; thus, also the operator performing the treatment was blinded.

To reduce bias caused by negative expectations that have been described to influence pain reports [15], in this study, both rLWD and sLWD groups started the treatment with the operator stating that the device was active.

rLWD, sLWD and manual massage treatments were applied with a neutral cream.

\section{Outcomes}

Each participant in the experiment was asked to answer a NPRS questionnaire before and after receiving the treatments as a primary outcome. The athletes were instructed that NPRS can range from 0 (no pain) to 10 (worst imaginable pain) and then asked to score their pain. The same score was requested immediately after they received the treatment. The NPRS has been provided to be a reliable tool for assessing the pain level in the musculoskeletal population [16]. 
The participants were also asked to answer a Patient Global Impression of Change Scale (PGIC) [17] questionnaire after undergoing treatment. In this sevenitem questionnaire, the participants could report to feel the following: "a great deal better," "much better," "moderately better," "somewhat better," "a little better," "almost the same," or to feel "no change or worst" after treatment.

\section{Data analyses}

In this study, data were analyzed using JASP 0.8 .6 for Mac 2018. An analysis of variance (ANOVA) was performed to compare the variability in post-treatment NPRS values among the groups and in pre- and posttreatment NPRS score differences among the groups, and a $p$ value lower than 0.05 was considered statistically significant.

Data were presented as pre- and post-treatment mean NPRS scores and were listed in relation to the frequency on the PGIC Scale. The proportion of reports in the PGIC Scale between the groups was calculated with the Kruskal-Wallis test.

The pre-treatment characteristics and proportions of the participants in the different treatment groups that attained a result equal to or better than the clinically relevant change in NPRS score were analyzed (Table 1).

The association between the PGIC Sale and NPRS scores was calculated using the Kendall tau $(\tau)$ rank correlation that ranged between - 1 (perfect inversion association) and 0 (absence of association). Values that ranged from 0 to -0.3 indicated a weak correlation, from -0.3 to -0.7 a moderate correlation; and $>-0.7$ a strong correlation.

\section{Results}

\section{Flow of participants}

The manual massage group was composed of 19 participants; the rLWD group, 17 participants; and the sLWD group of 19 participants.

The groups were comparable in relation to the demographic and pre-treatment outcome characteristics. The baseline characteristics are shown in Table 1 . The participants' ages ranged from 23 to 60 years (mean, $38.9 \pm 7.9$ years), and the mean pretreatment NPRS score in the manual massage, rLWD, and sLWD groups were 5.6/10, $5.7 / 10$, and 5.8/10, respectively.

All 55 athletes with lower limb DOMS completed the study (Fig. 2).

\section{Effects of interventions}

The descriptive statistics is shown in Table 1. The ANOVA of the post-treatment NPRS score showed no significant difference between the treatment group variability means $(p=0.91$ and $F=0.08)$. The ANOVA of the mean between the group variability pre- and posttreatment NPRS scores showed no significant difference $(p=0.79$ and $F=0.23$ ). Differences can be observed in the PGIC frequency reports (Fig. 3), although no significant differences can be found among the groups (Kruskal-Wallis, $p=0.638$ ).

The NPRS and PGIC Scale scores demonstrated a moderate correlation, as the Kendall tau rank correlation $(\tau)$ value was 0.34 .

\section{Discussion}

To the best of our knowledge, this is the first randomized controlled trial that compares the effectiveness of real LWD, sham LWD, and manual massage for lower limb DOMS. As outlined, in general, few data on the effects of LWD on musculoskeletal disorders exist in the literature despite a common massive performance of such technique in the clinical setting. As manual massage has been effective for treating DOMS [10, 18-20], we were interested to compare it with LWD and sham LWD. Similar results in DOMS attenuation have been described in high-quality studies (Physiotherapy Evidence Database PEDro score $\geq$ $6 / 10$ ) [21] that provided manual massage as a comparable modality to the one described in the present study. In the literature, the effects of electrotherapies on DOMS have been investigated without significant results; however, no studies have considered LWD [22-24]. In this study, although the proportion of participants who attained an

Table 1 Baseline and demographic characteristics of the participants and descriptive statistics. Values are expressed as mean (standard deviation). $\Delta=$ difference

\begin{tabular}{llll}
\hline & Group & & \\
\cline { 2 - 3 } & sLWD $n=19$ & rLWD $n=17$ & Massage $n=19$ \\
\hline Age, years & $36.6(6.8)$ & $39.4(7.4)$ & $40.8(9.2)$ \\
Pre-treatment NPRS score & $5.8(2.2)$ & $5.6(1.4)$ & $5.7(2.3)$ \\
$\begin{array}{l}\text { Post-treatment NPRS score } \\
\text { ANOVA, } F=023 \text { and } p=0.79\end{array}$ & $3.1(1.9)$ & $3.3(1.6)$ & $3.3(2.1)$ \\
$\begin{array}{l}\text { Pre-post treatment } \Delta \\
\text { ANOVA, } F=0.08 \text { and } p=0.91\end{array}$ & $2.7(2.0)$ & $2.3(1.5)$ & $2.4(1.2)$ \\
Relative proportion attaining a result equal or higher than 2 points in the pre-post treatment NPRS & $63,1 \%$ & $64.7 \%$ & $68.4 \%$ \\
\hline
\end{tabular}




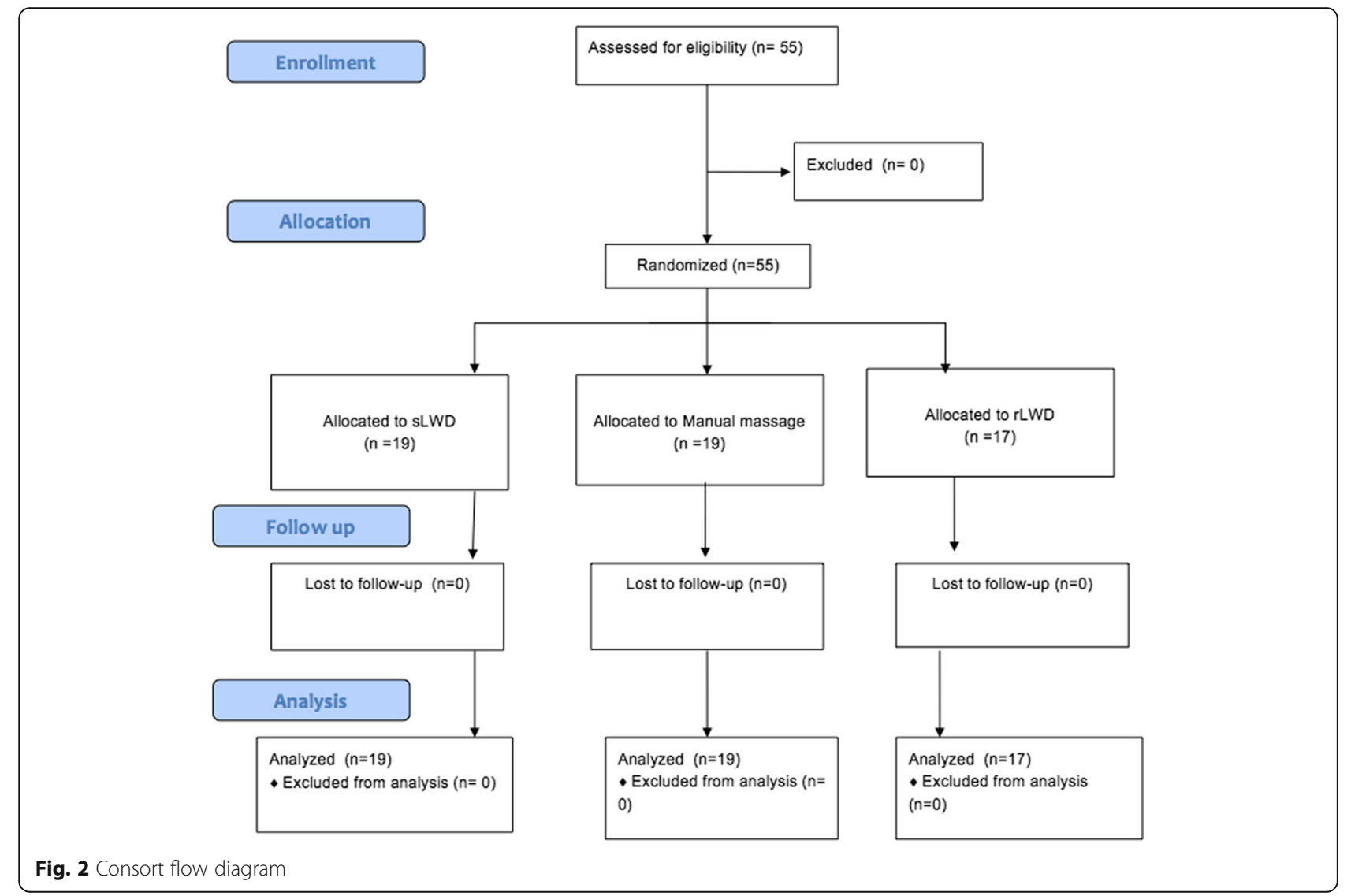

improvement of equal or more than NPRS points was higher in the manual massage group (Table 1), similar results were obtained for manual massage, rLWD, and sLWD, considering the post-treatment NPRS score or differences between the pre- and post-treatment NPRS scores. This suggests that the pain reduction reported by athletes with lower limb DOMS in the NPRS may not be attributable to the specific mechanism belonging exclusively to manual massage or LWD.
In the groups treated with LWD (both real or sham), a wider range of post-treatment-reported perceptions measured using the PGIC Scale was referred than in the manual massage group. The authors suggest the possibility that this outcome can be attributable to patient expectations in relation to treatment. Some athletes, both in the real and sham LWD groups, reported feeling "a great deal better" or "no change" or "worst" after treatment in the PGIC Scale, whereas in the manual massage



Fig. 3 Post-treatment Patient Global Impression of Change Scale scores 
group, the participants generally reported feeling "better" or "moderately better" after receiving the treatment. The literature described how expectations and persuasion can interfere with perceptions of an event, influencing individual output and behavioral responses [25, 26]: It could be of interest to the clinical practitioners to identify the participants who can benefit from the idea of receiving a strongly beneficial perceived treatment.

In the present study, after treatment, interventions as well as sham treatments produced similar results. An improvement of at least 2 points in NPRS score (Table 1) was achieved by $68 \%$ of participants receiving manual massage, by $64.7 \%$ receiving rLWD and by $63.1 \%$ of partecipants receiving sham LWD. This could be interesting for a sports team that is often engaged in traveling, as manual massage which is an easy-to-perform treatment not requiring adjunctive devices other than therapist's hand results in meaningful improvement in lower limb DOMS related pain. Other treatments such as wholebody cryotherapy and cold water immersion with similar results to the present study on DOMS reduction have been described [27], but these modalities are more demanding from a logistical point of view than manual massage or LWD, especially for those who are engaged in traveling.

\section{Limitations}

This study had several limitations, mainly related to the clinical context in which this data were acquired. Firstly, we did not defined a NPRS score as an inclusion criterion. This could have introduced heterogeneity among included participants; however, this was necessary in order to have the possibility to reach the a-priori calculated sample size. Secondly, we assessed the outcomes immediately after the provision of treatments, at rest, and no follow-up (short or medium term) was performed. This could lead to an overestimation of the treatment effects, as DOMS is typically present during the movement. We made this choice in order not to disturb excessively the athletes involved in the competition. For the same reason, the number of assessed outcome was restricted. In future studies, it would be of interest to include physical outcomes related to DOMS, such as pain on stretch, muscle strength, or other functional outcomes as suggested in other papers [27].

\section{Conclusions}

This study showed that manual massage, rLWD, and sLWD did not led to statistically significant changes in NPRS score of lower limb DOMS in ski mountaineering athletes. Future studies, including further outcomes measures, are justified in order to find more effectiveness treatments for the DOMS.

\section{Abbreviations}

ANOVA: Analysis of variance; DOMS: Delayed-onset muscle soreness;

LWD: Long-wave diathermy; NPRS: Numeric pain rating scale; PGIC: Patient global impression of change; SD: Standard deviation

\section{Acknowledgements}

Michela De Bona, Guido Giardini, Marco Barbero their advices and patience were fundamental for the realisation of the present study.

\section{Authors' contributions}

LV conception of the work, data acquisition and analysis, drafting. CF data acquisition. RC data acquisition. MT data acquisition. EM acquisition and analysis of data. GC work drafting and revisioning. All authors read and approved the final manuscript.

\section{Funding}

No applicable.

Availability of data and materials

Please contact author for data requests.

Ethics approval and consent to participate

Ethical approval was obtained from Comitato etico azienda ospedaliera Aosta prot. 6719 22/1/2015.

\section{Consent for publication}

Written consent was obtained from partecipants.

\section{Competing interests}

The authors declare that they have no competing interests.

\section{Author details}

${ }^{1}$ Studi fisioterapici di Montagna, Rue Palleusieux 111010 Pré-Saint-Didier, Aosta, Italy. ${ }^{2}$ Azienda Ospedaliera Maggiore della carità, Novara, Italy. ${ }^{3}$ Studi fisioterapici di Montagna, Trento, Italy. ${ }^{4}$ stituto clinico San Camillo, Torino, Italy. ${ }^{5}$ Università Torino Bachelor in Physiotherapy, Torino, Italy. ${ }^{6}$ Supsi Scuola Universitaria per la Svizzera Italiana, Lugano, Switzerland.

Received: 26 May 2018 Accepted: 17 December 2019

Published online: 15 January 2020

\section{References}

1. Lewis PB, Ruby D, Bush-Joseph CA. Muscle soreness and delayed-onset muscle soreness. Clin Sports Med. 2012:31:255-62

2. Vickers AJ. Time course of muscle soreness following different types of exercise. BMC Musculoskelet Disord. 2001;2:5.

3. Yu JG, Liu JX, Carlsson L, Thornell LE, Stål PS. Re-evaluation of sarcolemma injury and muscle swelling in human skeletal muscles after eccentric exercise. PLoS One. 2013;8:e62056.

4. Proske U, Allen TJ. Damage to skeletal muscle from eccentric exercise. Exerc Sport Sci Rev. 2005;33:98-104.

5. Vila-Chã C, Hassanlouei H, Farina D, Falla D. Eccentric exercise and delayed onset muscle soreness of the quadriceps induce adjustments in agonistantagonist activity, which are dependent on the motor task. Exp Brain Res. 2012;216:385-95.

6. Cheung K, Hume P, Maxwell L. Delayed onset muscle soreness: treatment strategies and performance factors. Sports Med. 2003;33:145-64.

7. Costello JT, Baker PR, Minett GM, Bieuzen F, Stewart IB, Bleakley C. Wholebody cryotherapy (extreme cold air exposure) for preventing and treating muscle soreness after exercise in adults. Cochrane Database Syst Rev. 2015; 9:CD010789.

8. Malanga GA, Yan N, Stark J. Mechanisms and efficacy of heat and cold therapies for musculoskeletal injury. Postgrad Med. 2015:127(1):57-65.

9. Bakowski P, Musielak B, Sip P, Biegański G. Effects of massage on delayedonset muscle soreness. Chir Narzadow Ruchu Ortop Pol. 2008;73:261e265.

10. Guo J, Li L, Gong Y, Zhu R, Xu J, Zou J, et al. Massage alleviates delayed onset muscle soreness after strenuous exercise: a systematic review and meta-analysis. Front Physiol. 2017;8:747.

11. Han JH, Kim MJ, Yang HJ, Lee YJ, Sung YH. Effects of therapeutic massage on gait and pain after delayed onset muscle soreness. J Exerc Rehabil. 2014; 10:136-40. 
12. Visconti L, Capra G, Carta G, Forni C, Janin D. Effect of massage on DOMS in ultramarathon runners: a pilot study. J Bodyw Mov Ther. 2015;19:458-63.

13. Duñabeitia I, Arrieta H, Torres-Unda J, Gil J, Santos-Concejero J, Gil SM, et al. Effects of a capacitive-resistive electric transfer therapy on physiological and biomechanical parameters in recreational runners: a randomized controlled crossover trial. Phys Ther Sport. 2018;32:227-34.

14. Salaffi F, Stancati A, Silvestri CA, Ciapetti A, Grassi W. Minimal clinically important changes in chronic musculoskeletal pain intensity measured on a numerical rating scale. Eur J Pain. 2004;8:283-91.

15. Colloca L. Nocebo effects can make you feel pain. Science. 2017;358:44.

16. Karcioglu O, Topacoglu H, Dikme O, Dikme O. A systematic review of the pain scales in adults: which to use? Am J Emerg Med. 2018;36:707-14. https://doi.org/10.1016/j.ajem.2018.01.008 Epub 2018 Jan 6.

17. Guy W. Assessment manual for psychopharmacology. DHEW Publication No. ADM 352 76-338. U.S. Washington, DC: Government Publishing Office; 1976.

18. Zainuddin Z, Newton M, Sacco P, Nosaka K. Effects of massage on delayedonset muscle soreness, swelling, and recovery of muscle function. J Athl Train. 2005;40:174-80.

19. Dupuy O, Douzi W, Theurot D, Bosquet L, Dugué B. An evidence-based approach for choosing post-exercise recovery techniques to reduce markers of muscle damage, soreness, fatigue, and inflammation: a systematic review with meta-analysis. Front Physiol. 2018;9:403.

20. Nelson N. Delayed onset muscle soreness: is massage effective? J Bodyw Mov Ther. 2013;17:475-82.

21. Andersen $\mathrm{L}$, Jay $\mathrm{K}$, Andersen $\mathrm{CH}$, Jakobsen $\mathrm{MD}$, Sundstrup $\mathrm{E}$, Topp $\mathrm{R}$, et al. Acute effects of massage or active exercise in relieving muscle soreness: randomized controlled trial. J Strength Cond Res. 2013;27:3352-9.

22. Craig JA, Bradley J, Walsh DM, Baxter GD, Allen JM. Delayed onset muscle soreness: lack of effect of therapeutic ultrasound in humans. Arch Phys Med Rehabil. 1999:80:318-23.

23. Craig JA, Cunningham MB, Walsh DM, Baxter GD, Allen JM. Lack of effect of transcutaneous electrical nerve stimulation upon experimentally induced delayed onset muscle soreness in humans. Pain. 1996;67:285-9.

24. Craig JA, Barron J, Walsh DM, Baxter GD. Lack of effect of combined low intensity laser therapy/phototherapy (CLILT) on delayed onset muscle soreness in humans. Lasers Surg Med. 1999:24:223-30.

25. Benedetti F. Placebo effects: from the neurobiological paradigm to translational implications. Neuron. 2014:84:623-37.

26. Klucharev V, Smidts A, Fernández G. Brain mechanisms of persuasion: how "expert power" modulates memory and attitudes. Soc Cogn Affect Neurosci. 2008:3:353-66

27. Glasgow PD, Ferris R, Bleakley CM. Cold water immersion in the management of delayed-onset muscle soreness: is dose important? A randomised controlled trial. Phys Ther Sport. 2014;15:228-33.

\section{Publisher's Note}

Springer Nature remains neutral with regard to jurisdictional claims in published maps and institutional affiliations.

Ready to submit your research? Choose BMC and benefit from:

- fast, convenient online submission

- thorough peer review by experienced researchers in your field

- rapid publication on acceptance

- support for research data, including large and complex data types

- gold Open Access which fosters wider collaboration and increased citations

- maximum visibility for your research: over $100 \mathrm{M}$ website views per year

At $\mathrm{BMC}$, research is always in progress.

Learn more biomedcentral.com/submissions 